\title{
Detection of Weligama Coconut Leaf Wilt Disease Phytoplasma by Real-Time Polymerase Chain Reaction
}

\author{
H.T.R. Wijesekara ${ }^{1 *}$, S.A.C.N. Perera ${ }^{2}$, D. Bandupriya ${ }^{3}$ \\ M.K. Meegahakumbura ${ }^{1}$ and Lalith Perera ${ }^{1}$
}

\begin{abstract}
Weligama Coconut Leaf Wilt Disease (WCLWD) is a non-lethal, but debilitating phytoplasma disease found in coconut palms in Sri Lanka which is confined to the Southern Province of the country, well-away from the major coconut growing area. If it spreads to the major coconut growing area, it might severely damage the coconut industry in Sri Lanka. Government commenced a disease control program to eradicate the disease and, more importantly to prevent spreading of the disease to major coconut growing areas. The major constraint in this program is the lack of an accurate and reliable method for identifying affected palms. Visual symptoms are used to identify the affected palms for removal, yet growers are not always convinced of the method of resisting palm removal. This poses a serious threat to the implementation of the disease control program. Although a Nested-PCR-based disease diagnosis was established earlier, the detection rate and reliability need further improvements. Therefore, an urgent necessity for a more reliable disease detection method has arisen. In the current study, a RealTime Polymerase Chain Reaction (qPCR) powered by a pair of primers and a probe designed from the published partial sequences of the WCLWD phytoplasma was validated with 202 coconut samples and a detection rate of above $95 \%$ was achieved. This newly established detection system was highly reliable and a way forward for controlling the WCLWD disease in Sri Lanka.
\end{abstract}

Key words: Coconut, weligama coconut leaf wilt disease, phytoplasma detection, qPCR

\section{Introduction}

Weligama Coconut Leaf Wilt Disease (WCLWD) was first reported in the Weligama area of the Matara district of Sri Lanka in late 2006. Later it was found that WCLWD has spread to all coconut growing Divisional Secretariat (DS) regions in Matara and four DS regions each in Galle and Hambantota districts in Southern Province (Wijesekara et al., 2008). WCLWD is a debilitating phytoplasma disease of coconut which poses an alarming threat to coconut industry in Sri Lanka. In the survey conducted by Coconut Cultivation Board (CCB) the yield loss due to WCLWD has been estimated as 18\%, 2.42\% and $25.87 \%$ in Galle, Hambantota and Matara districts, respectively. The reduction in kernel weight of severely WCLWD affected and leaf rot affected palms were $40 \%$ and $70 \%$, respectively (Nainanayaka and Ranasinghe 2013).

The government has decided to remove the affected coconut palms to prevent its spread to major coconut growing area, termed as "the coconut triangle" which included $75 \%$ of the total coconut growing areas the country. Identification of affected palms was mainly based on the three prominent visual symptoms in the crown; flaccidity of leaf blade, uneven yellowing of fronds in the crown and marginal necrosis of leaflets. Bud leaves of some of the WCLWD affected palms were prone to be infected by a complex of fungi causing leaf rot disease as the final stage of the disease (Wijesekara et al., 2008;

\footnotetext{
${ }^{1}$ Coconut Research Institute, Sri Lanka.

${ }^{2}$ University of Peradeniya, Sri Lanka

${ }^{3}$ University of Colombo, Sri Lanka

${ }^{*}$ Corresponding Author
} 
Wijesekara and Fernando 2013). Since yellowing of coconut fronds occurs due to various reasons, such as nutrient deficiencies, moisture deficit, etc., the identification of affected palms by visual symptoms alone is challenging.

During the palm removal program, some growers disagree with removing diseased palms because some of the marked palms are unaffected by the disease but the symptoms are due to some other reasons. In 2012, a Nested PCR based detection system was developed for the identification of diseased palms (Perera $e t$ al., 2012). However, the detection percentage of the palms showing visual symptoms of WCLWD by Nested PCR system was around $85 \%$ during rainy season. This level of accuracy was found to be inadequate for the reliable detection of suspected WCLWD palms (Wijesekara et al., 2013). Many workers have identified PCR based method can be used in routine identification of phytoplasma infections in several crops including tree crops (Deng and Hiruki 1990, Gundesen and Lee 1996). Therefore, a more reliable diagnostic technique for detecting WCLWD affected palms aroused and the use of Real Time Polymerase Chain Reaction (qPCR) was investigated.

\section{Method and Materials}

Milky white bud leaf samples of WCLWD affected palms were collected from different lands of disease-affected areas. Healthy samples were collected from Isolated Seed Garden (ISG), Ambakelle and Pallama Seed Gardens situated in North Western Province far away from the disease affected area where disease has never been reported. A total of 202 affected and 70 healthy coconut samples were collected for the experiment during the period of two years, from 2013 and 2014. DNA from white leaf disease affected sugarcane plants was used as positive controls to check the PCR reactions.

Bud leaf samples were surface sterilized with $70 \%$ alcohol and mid rib of the leaflets (ekel) were collected for the DNA extraction. Ekel was cut into small pieces and ground to a fine powder in liquid nitrogen. Total DNA was extracted by CTAB method (Sambrook et al., 1982) with slight modification (Perera et al., 1999). Composition of the extraction buffer was 0.05 moles Tris, 0.01 moles EDTA, 0.7 moles $\mathrm{NaCl}, \mathrm{CTAB} 10 \mathrm{~g}$ and final volume $500 \mathrm{ml}$ at $\mathrm{pH}$ 8; $2 \%$ monothioglycerol was added just before use. One gram of ekel powder was added into $2 \mathrm{ml}$
Eppendorf tube with $1 \mathrm{ml}$ of extraction buffer at 65 0C. The powdered ekal was mixed well with buffer and incubated at $650 \mathrm{C}$ for 30 minutes thoroughly mixing at 10 -minute intervals. Tubes were allowed to cool to room temperature and $1 \mathrm{ml}$ of chloroform: isoamyl alcohol (24:1) mixture was added and thoroughly mixed. Tubes were centrifuged at $13000 \mathrm{rpm}$ for 15 minutes in a refrigerated centrifuge (Remi, India) at $40 \mathrm{C}$. The aqueous phase was pipetted into fresh $1.5 \mathrm{ml}$ eppendorf tubes, equal volume of chloroform: isoamyl alcohol mixture added and centrifuged similarly. The aqueous phase was again pipetted into a fresh $1.5 \mathrm{ml}$ tube and 0.6 volume of chilled isopropanol was added. Content was gently mixed by inverting the tubes and kept in a freezer (4 0C) overnight for maximum precipitation of DNA. Tubes centrifuged at $13000 \mathrm{rpm}$ for 15 minutes at 4 $0 \mathrm{C}$ and the supernatant was decanted. The pellet was washed with $80 \%$ ethanol and centrifuged at $13000 \mathrm{rpm}$ for 5 minutes. Extra alcohol was drained and the pellet was dried for half an hour in a vacuum until the alcohol smell disappears. Thirty microliter of TE buffer $(10 \mathrm{mM}$ Tris $\mathrm{HCl}$, 1 mM EDTA; pH 8) was added and kept in room temperature overnight for dissolving of the DNA. DNA was stored in a deep freezer at - $200 \mathrm{C}$ until further use.

Quantitative PCR (qPCR) master mixture based on Taqman chemistry was purchased from the manufacturer Applied Biosystems Inc. USA. A pair of qPCR primers was designed based on the published partial sequences of 16SrRNA gene (EU635503, GQ121047) of WCLWD phytoplasma. The sequences of forward, reverse primers and the probe are RTWF 5' AGCCCCGGCAAACTATGTG, RTWR 5'AACGCTCGCCCCCTATG and 6' FAMCAGCAGCCGCGGTA- MGB respectively. The PCR mixture consisted of Taqman master mix 7.5 $\mu \mathrm{l}$, primers $0.15 \mu \mathrm{M}$ each, water $0.57 \mu \mathrm{l}$, probe $0.15 \mu \mathrm{M}$ and DNA $30-50 \mathrm{ng}$. Reaction mixture was dispensed into wells of optical PCR plates and covered with optical adhesive film prior to inserting into the instrument. The reaction was carried out in an Applied Biosystems 7500 RealTime PCR instrument under standard conditions. Initially reaction mixture was optimized using 2 - $5 \mu \mathrm{l}$ of DNA from white leaf disease affected sugarcane plants. Fifty one symptomatic coconut DNA, 2 white leaf sugarcane DNA and 4 healthy coconut DNA samples were used to get optimum DNA concentration in the mixture. The test was validated with 70 healthy and 132 symptomatic coconut palm DNA samples. 


\section{Results and Discussion}

It was found that use of $2.0 \mu$ lof white leaf diseased sugar cane DNA sample (contained about 50 ng of DNA) produced pronouncing amplification plot. The cycle threshold values of different volumes of white leaf sugarcane DNA is indicated in Table 1 . The results showed that increase in DNA content does not give significantly higher CT values.

\begin{tabular}{|c|c|c|c|c|}
\hline & $\begin{array}{c}\text { Sugarcane } \\
\text { DNA2 } \mu \mathrm{l}\end{array}$ & $\begin{array}{c}\text { Sugarcane } \\
\text { DNA } 3 \mu l\end{array}$ & 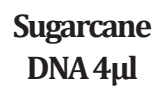 & $\begin{array}{c}\text { Injection } \\
\text { water }\end{array}$ \\
\hline $\begin{array}{l}\text { CT } \\
\text { value } \\
\end{array}$ & 18.6773 & 17.7254 & 17.6905 & 35.9934 \\
\hline
\end{tabular}

Table 1. Average cycle threshold values of white leaf affected sugarcane DNA samples in Real-Time PCR

The best WCLWD affected coconut DNA volume was found to be $3.75 \mu \mathrm{l}$ with lower cycle threshold value than other DNA volumes. In the validation reactions, initially false negative percentage was higher in number than positive samples which were collected during the dry season of the year. The percent positive symptomatic samples $(\mathrm{n}=51)$ collected during the dry period (February - September months) and rainy (wet) period (October -January months) of the year are given in Table 2. The four healthy samples didn't produce false positives.

\begin{tabular}{lcc}
\hline $\begin{array}{l}\text { Sampling } \\
\text { Period }\end{array}$ & $\begin{array}{c}\text { Symptomatic } \\
\text { samples }\end{array}$ & $\begin{array}{c}\text { Healthy } \\
\text { samples }\end{array}$ \\
\hline Dry & $21.43(\mathrm{n}=51)$ & 0.0 \\
Wet (rainy) & $83.0(\mathrm{n}=151)$ & 0.0 \\
\hline
\end{tabular}

Table 2. Percent of symptomatic samples produced positive signals with qPCR tests during dry and wet periods

In the validation experiments, $96.2 \%$ of 132 DNA from symptomatic coconut palms were identified as affected and 98.1\% DNA samples from healthy coconut palms identified as unaffected by qPCR. Only 3.8\% affected and 1.9\% healthy coconut samples were detected as false negatives and false positives, respectively. In biological tests, $95 \%$ accuracy is sufficient to consider as positive.

Perera et al., (2012) have reported that low detection rate of phytoplasma in symptomatic coconut palms was due to low titre of phytoplasma in the coconut tissues.
It has been reported that phytoplasma translocate to different places of the affected plants during different seasons of the year, for example, grape vine phytoplasma move towards roots during winter season (Constable et al., 2003). Similarly, WCLWD phytoplasma also may move towards root-bole region where the temperature fluctuation is lesser than that of the canopy of the coconut palm. By staining of thin sections of rachilla, it was observed that the distribution of phytoplasma in all cells is not even (Fig. 1) (Wijesekara, and Fernando, 2013). It has also been observed that detection rates decreased in summer in Kerala, India with the Kerala Wilt affected coconut palms. The symptoms of Kerala Wilt disease in India are very much similar to that of WCLWD. The maximum detection rate of Kerala Wilt has been achieved during the winter months (personal communication with Dr. R. Manimekalai). Although phytoplasma enrichment procedure was tested for samples collected during the dry periods, the detection rate improvement was not significant. Wijesekara et al., (2013) has obtained less than $85 \%$ detection rate of WCLWD samples with the nested PCR.

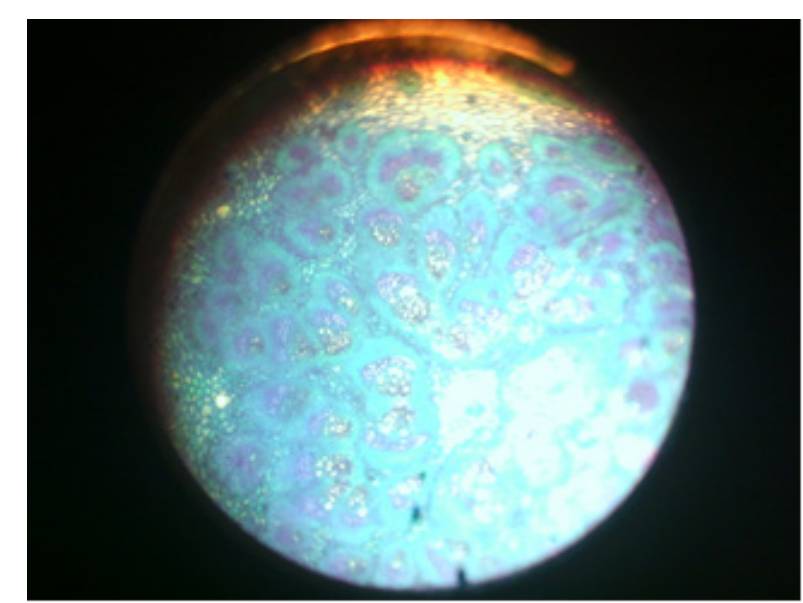

Figure 1. Thin sections of rachilla of WCLWD affected coconut inflorescence stained with Dienes stain showing uneven distribution of phytoplasma in sieve tubes (purple patches are phloem tissues with phytoplasma) (magnification $10 \times 10$ )

It is essential to sequence PCR products generated by universal phytoplasma specific primers based on 16S rRNA gene, as many gram positive bacterial sequences tend to get amplified with those primers. The low rates of detection of symptomatic coconut samples in nested PCR are mainly due to lower sensitivity of nested PCR method. But current study 
with RT PCR revealed that more than $96 \%$ of symptomatic palms detected as affected palms. This high rate of detection was achieved due to high sensitivity of the method and the specificity of the primers and probe developed for WCLWD. The undetected $4 \%$ symptomatic palms may be due to misidentification of nutrient deficient palms as affected palms or the phytoplasma titer in sampled tissue is very low. The detection rate of $98.1 \%$ in healthy palm category as unaffected is higher than that detect affected palms is a good indication of the accuracy of the test. Further, it indicates that qPCR primers RTWF/R together with 6' FAM MGB probe were more specific in detection of WCLWD phytoplasma (Table 3). Such a high detection rate is highly valuable in solving disputes in marking affected palms for eradicating the programme.

The DNA samples with higher titer of phytoplasma DNA show amplification with lesser number of PCR cycles (figure 2). The detection of sugarcane white leaf disease with same primers and the probe indicate that the regions of the gene used for the development of primers and probe are common to both phytoplasma species. These primers and probe can be considered as group specific primers and probes giving amplification with phytoplasmas with rice yellow dwarf group origin.

\begin{tabular}{lcccc}
\hline $\begin{array}{c}\text { Sample } \\
\text { type }\end{array}$ & $\begin{array}{c}\text { Percent } \\
\text { positive }\end{array}$ & $\begin{array}{c}\text { False } \\
\text { positive }\end{array}$ & $\begin{array}{c}\text { False } \\
\text { negative }\end{array}$ & $\begin{array}{c}\text { Detection } \\
\text { rate }\end{array}$ \\
\hline $\begin{array}{l}\text { Sympto- } \\
\text { matic }\end{array}$ & 96.2 & 0 & 3.8 & 96.2 \\
Healthy & 0 & 1.9 & 0 & 98.1 \\
\hline
\end{tabular}

Table 3. Reaction of the samples in the qPCR validation experiment

Amplification of DNA samples above 35 cycles are considered as unspecified amplification or negative samples. According to the qPCR results, selection of WCLWD affected palms by visual observations by a trained person is of with high degree of accuracy.

\section{Conclusion}

WCLWD Phytoplasma detection rate varies with different seasons; the rainy and the dry season. Low detection rate was observed during dry period and detection improves with the onset of rains. The primers and the probe designed for qPCR are highly specific and it detects more than $95 \%$ of symptomatic palms as disease affected palms. Therefore, this test can be used for screening of suspected WCLWD palms in the disease eradication program. This study also confirmed that disease identification based on all three crown visual symptoms is also a quick and reliable alternative for the disease screening.

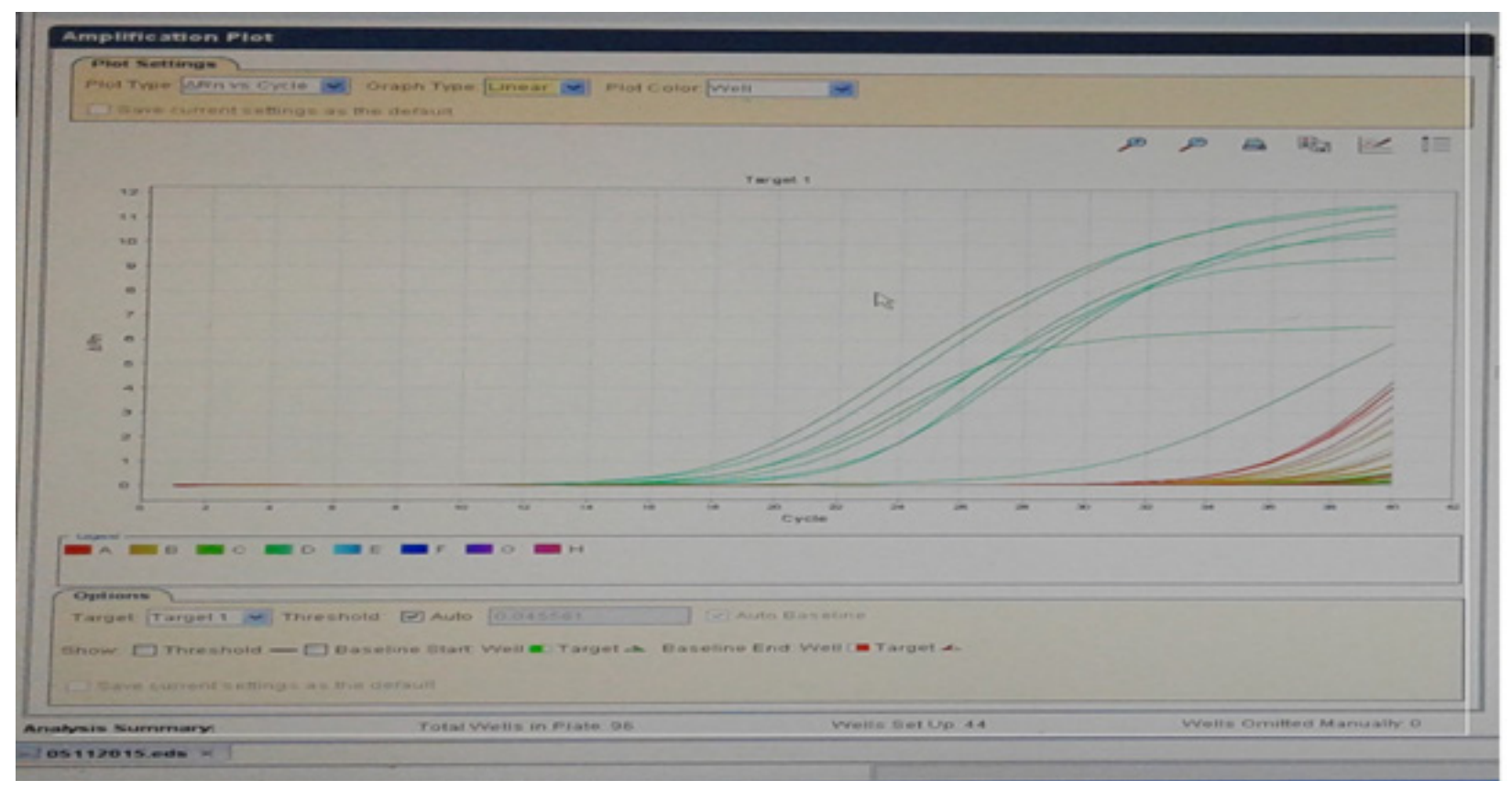

Figure 2. Amplification plot yielding by PCR reaction in Real-Time PCR machine 


\section{Acknowledgments}

The authors gratefully acknowledge the financial assistance provided by FAO from the Technical Corporation Project 3303 to support WCLWD research and development program to carry out this experiment at CRI. The authors also wish to acknowledge the assistance from the Sugarcane Research Institute, Udawalawe by supplying white leaf sugarcane samples to this study whenever necessary.

\section{References}

Ahrens, U. and Seemuller, E. 1992. Detection of DNA of plant pathogenic mycoplasma like organisms by a polymerase chain reaction which amplifies sequence of the 16S rRNA gene. Phytopath, 82, $828-832$.

Constable, F. E., Gibb, K. S. and Symons, R. H. 2003. Seasonal distribution of phytoplasmas in Australian grapevines. Plant Pathol., 52: $267-276$.

Nainanayaka, N. P. A. D. and Ranasinghe, C. S. 2013. Physiological/Biochemical effects of WCLWD on palm and its production. In: Weligama Coconut Leaf Wilt Disease. Six years after. Eds. H. P. M. Gunasena, H. A. J. Gunathilaka, L. C. P. Fernando, J. M. D. T. Everard and P. A. H.N. Appuhamy. Coconut Research Institute of Sri Lanka, Lunuwila, Sri Lanka. pp. 31-47.

Perera, L., Russell, J. R., Provan, J. and Powell, W. 1999. Identification and characterization of microsatellites in coconut (Cocos nucifera L.) and analysis of coconut population in Sri Lanka. Molecular Ecology, 8: 344 - 346.

Perera, L., Meegahakumbura, M. K., Wijesekara, H. T. R., Fernando, W. B. S. and Dickinson, M. J. 2012. A phytoplasma is associated with the Weligama coconut leaf wilt disease in Sri Lanka. J. Pl. Pathol., 94(1): 205 - 209.
Ramjegathesh, R. Karthikeyan, G., Rajendran, L., Johnson, I., Raguchander, T. and Samiyappan, R. 2012. Root wilt disease of coconut palms in South Asia - An Overview. Archives of Phytopathology and Plant Protection, 45(20): 2485-2493.

Sambrook, J., Fritsch, E. and Maniatis, T. 1982. Molecular Cloning. A Laboratory Manual. Cold Spring Harbor laboratory press, NY, USA, $6.3-6.6$ and $14.34-14.5$.

Wijesekara, H. T.R. , Perera, L., Wickramananda, I. W., Herath, I., Meegahakumbura, M. K., Fernando, W. B. S. and De Silva, P. H. P. R. 2008. Preliminary investigation on Weligama Coconut Leaf Wilt Disease: A new disease in Southern Sri Lanka. In: Proc. Second Symp. Plantation Crop Res. - Export competitiveness through quality improvements. Eds. N. A. D. P. Nainanayake and J. M. D. T. Everard. Coconut Research Institute, Lunuwila, Sri Lanka. pp. $336-341$.

Wijesekara, H. T. R. and Fernando, L. C. P. 2013. Symptoms and Etiology of Weligama coconut leaf wilt disease. In: Weligama Coconut Leaf Wilt Disease. Six years after. Eds. H. P. M. Gunasena, H. A. J. Gunathilaka, L. C. P. Fernando, J. M. D. T. Everard and P. A. H. N. Appuhamy. Coconut Research Institute of Sri Lanka, Lunuwila, Sri Lanka. pp. $18-25$.

Wijesekara, H. T. R., Perera, A. A. F. L. K., Meegahakumbura, M. G. M. K., Dassanayaka, E. M. and Ranasinghe, C. (2013). Serological and Molecular Techniques. In: Weligama Coconut Leaf Wilt Disease. Six years after. Eds. H. P. M. Gunasena, H. A. J. Gunathilaka, L. C. P. Fernando, J. M. D. T. Everard and P. A. H. N. Appuhamy. Coconut Research Institute of Sri Lanka, Lunuwila, Sri Lanka. pp. $56-62$. 